\title{
Conditioned defensive burying in rodents: Organismic variables
}

\author{
DALLAS TREIT, LORI J. TERLECKI, and JOHN P. J. PINEL \\ University of British Columbia, Vancouver, British Columbia V6T 1W5, Canada
}

\begin{abstract}
Conditioned defensive burying was observed in 30-, 60-, and 90-day-old male and female Long-Evans hooded rats (Experiment 1), in adult male and female CD-1 albino mice and LongEvans hooded rats (Experiment 2), and in adult male Long-Evans, Wistar, and Fischer rats and CD-1 and CF-1 albino mice (Experiment 3). Conversely, conditioned defensive burying was never observed in gerbils or hamsters and did not reach significant levels in BALB mice.
\end{abstract}

Pinel and Treit (1978) recently reported the discovery of a particularly robust form of aversive conditioning: conditioned defensive burying. Rats shocked once by one of two wire-wrapped prods mounted on opposite walls of a test chamber selectively buried the shock prod with bedding from the floor of the chamber during a subsequent test; in fact, every rat spent substantially more time burying the shock prod than burying the identical control prod. Pinel and Treit (1978) attributed the exceptional speed, selectivity, and reliability of this form of aversive conditioning to the fact that the aversive stimulus was delivered from a well-defined source (i.e., the shock prod) rather than through the usual grid floor. Conditioned defensive burying is a particularly important experimental phenomenon because it constitutes the first clear demonstration that rats can "avoid" conditioned stimuli in aversive conditioning situations by approaching and coping with them rather than by freezing or fleeing.

Subsequent research on conditioned defensive burying has established its remarkable generality as well as confirming its robustness. Conditioned defensive burying is not restricted to a particular type of aversive stimulus (Terlecki, Pinel, \& Treit, 1979; Wilkie, MacLennan, \& Pinel, 1979), intensity of shock (Treit, Pinel, \& Terlecki, 1980), size of chamber (Pinel, Treit, Ladak, \& MacLennan, 1980), conditioning-test interval (Pinel \& Treit, 1978; Pinel, Treit, \& Wilkie, 1980), or burying material (Pinel \& Treit, 1979). However, there has been no systematic attempt to assess the effects of organismic variables on conditioned defensive burying. Accordingly, the purpose of the following three experiments was to assess the effects of age, sex, species, and strain on conditioned defensive burying in rodents. The purpose was not so much to answer specific questions about conditioned defensive burying as it was to identify potentially fruitful areas of research.

This work was supported by a Natural Sciences and Engineering Research Council of Canada grant awarded to John Pinel. The authors are indebted to A. John MacLennan and Ferial Ladak for their assistance.

\section{EXPERIMENT 1}

The purpose of Experiment 1 was to determine whether the amount of conditioned defensive burying by rats is influenced by their age and sex. Of particular interest was the comparison between prepubertal and postpubertal rats (i.e., between rats younger and older than 35 days of age).

\section{Method}

The subjects, purchased from Canadian Breeding Farm and Laboratories, La Prairie, Quebec, were 30 male and 30 female Long-Evans hooded rats that were $30(n=20), 60(n=20)$, or $90(n=20)$ days of age. The subjects were housed in groups of five in white polyethylene cages $(50 \times 40 \times 20 \mathrm{~cm})$, the floors of which were covered with San-i-cel, a commercial bedding material made of ground corn cob (Paxton Processing Company, Paxton, Illinois). The subjects in each cage were the same age and sex. Purina laboratory chow and water were available continuously in the home cages.

All subjects were placed in a $44 \times 30 \times 44 \mathrm{~cm}$ Plexiglas test chamber in groups of five for 30-min periods on each of 4 consecutive days. Throughout all phases of the experiment, $5 \mathrm{~cm}$ of the commercial bedding material (San-i-cel) evenly covered the chamber floor. On Day 5, just prior to the conditioning phase of the experiment, a black, wire-wrapped prod was mounted through a hole at one end of the test chamber, $2 \mathrm{~cm}$ above the level of the bedding material. When each subject first touched this prod with a forepaw, it was shocked from an $800-\mathrm{V}$ source in series with a $160-\mathrm{kohm}$ resistor. The shock was turned on by the experimenter once good forepaw contact was made with the prod, and it was terminated by the withdrawal of the subject. The shocks were monitored by a storage oscilloscope, and they were found to average $4.9 \mathrm{~mA}(\mathrm{SD}=.79)$ in intensity and $32.7 \mathrm{msec}(\mathrm{SD}=15.3)$ in duration. Immediately following the shock, a 15-min test session was initiated, during which the behavior of each subject was monitored via closedcircuit television by an experimenter outside the testing room. The duration of burying behavior (i.e., the amount of time each rodent spent spraying the bedding material toward the shock prod with its forepaws) was recorded on an event recorder. Davis and Rossheim (1980) and Pinel, Treit, and Wilkie (1980) have established that the interobserver reliability of this duration of burying measure is extremely high: .93 and .988 , respectively.

\section{Results and Discussion}

Figure 1 shows that the male and female rats in all three age groups engaged in defensive burying behavior 


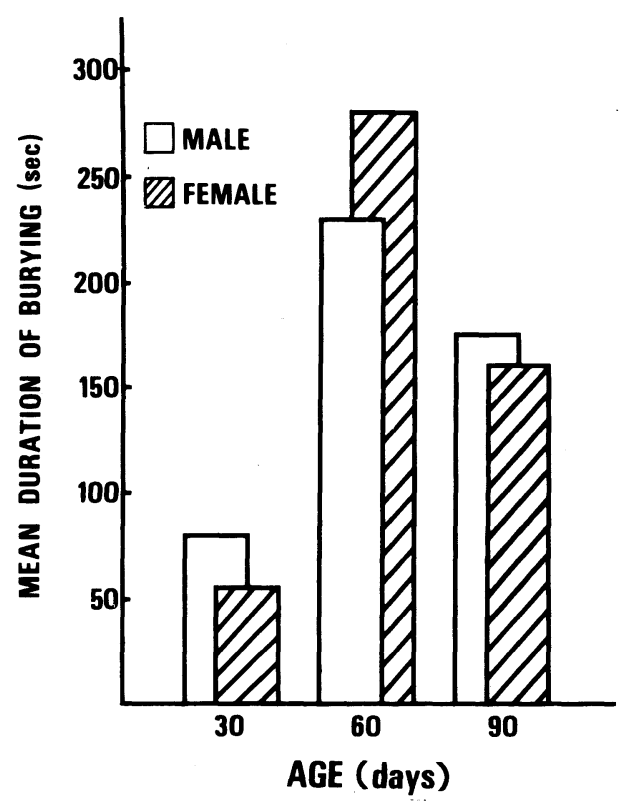

Figure 1. Mean duration of burying the shock prod by male and female Long-Evans hooded rats 30, 60, and 90 days of age.

after being shocked. All 40 postpubertal rats and 18 of 20 (9 male and 9 female) prepubertal rats sprayed some San-i-cel toward the shock source. In view of their small size, the behavior of the 30-day-old rats was particularly striking. One even managed to accumulate a pile of San-i-cel $10 \mathrm{~cm}$ high over the prod. The sex of the animals did not appear to have a substantial effect on the performance of the subjects in any of the three age groups.

A 2 by 3 analysis of variance performed on the duration of burying scores revealed a significant main effect of age $[F(2,54)=21.2, p<.001]$ but no significant sex $[\mathrm{F}(1,54)=.1, \mathrm{p}>.5]$ or interaction $[\mathrm{F}(1,54)=1.3$, $\mathrm{p}>$.1] effects. Subsequent Newman-Keuls tests $(\alpha=.05)$ established that both the 60- and the 90-day-old rats spent significantly more time burying the prod than did the 30-day-old rats and that the 60-day-old rats buried significantly more than did the 90-day-old rats.

The most impressive result of Experiment 1 was that almost all of the 30-day-old rats engaged in conditioned defensive burying. However, the fact that rats begin to leave the nest at 30 days of age (Calhoun, 1962) suggests that the early development of this defensive behavior may not be without adaptive significance.

\section{EXPERIMENT 2}

The purpose of Experiment 2 was to determine whether conditioned defensive burying is common to four species of rodents frequently employed in behavioral experiments (i.e., rats, mice, hamsters, and gerbils).

\section{Method}

Ten naive adult subjects composed each of eight groups. They were male $(260-$ to $300-\mathrm{g})$ and female $(210-$ to $250 \mathrm{~g})$
Long-Evans hooded rats, male (30- to $35-\mathrm{g}$ ) and female (23- to $29-\mathrm{g})$ CD-1 albino mice, male (95- to $115-\mathrm{g})$ and female (100- to $120 \mathrm{~g}$ ) Syrian golden hamsters, and male (75- to $90 \mathrm{~g})$ and female (65- to 85-g) Mongolian gerbils. The rats, mice, and hamsters were purchased from Canadian Breeding Farm and Laboratories, La Prairie, Quebec; the gerbils were purchased from High Oak Ranch, Goodwood, Ontario. Feeding and housing conditions were the same as those of Experiment 1. The subjects in each home cage were homogeneous with respect to species and sex.

The habituation procedures were similar to those used in Experiment 1. However, the conditioning and testing procedures were modified in one major respect; each subject was conditioned and tested in the presence of two prods (black and white) that had been mounted at opposite ends of the chamber following the habituation phase of the experiment. Each subject was shocked by one of these two prods, and the duration of burying directed at each of the prods was recorded separately during the subsequent $15-\mathrm{min}$ test session. Five of the subjects in each group were shocked by the white prod, and five were shocked by the black prod. The particular prod that would serve as the shock prod for a particular subject was randomly determined before the commencement of the conditioning phase.

In order to minimize the possible confounding effects of pheromones on the defensive burying response, the test chambers were emptied after each test session, washed with a $20 \%$ alcohol solution, and refilled to a depth of $5 \mathrm{~cm}$ with fresh San-i-cel.

\section{Results and Discussion}

Both the rats and mice selectively buried the source of shock (see Figure 2), whereas the gerbils and hamsters did not. All 20 of the rats and 18 of the 20 mice moved some bedding material toward the shock source, but not one of the gerbils or hamsters displayed this response at any time during the experiment. A sex by species analysis of variance of the duration of burying directed toward the shock prod confirmed the significance of the differences between the species $[F(3,72)=49.50$, $\mathrm{p}<.0001]$. However, there was no significant difference between males and females in the amount they buried $[F(1,72)=.57, \mathrm{p}>.45]$ and no significant interaction

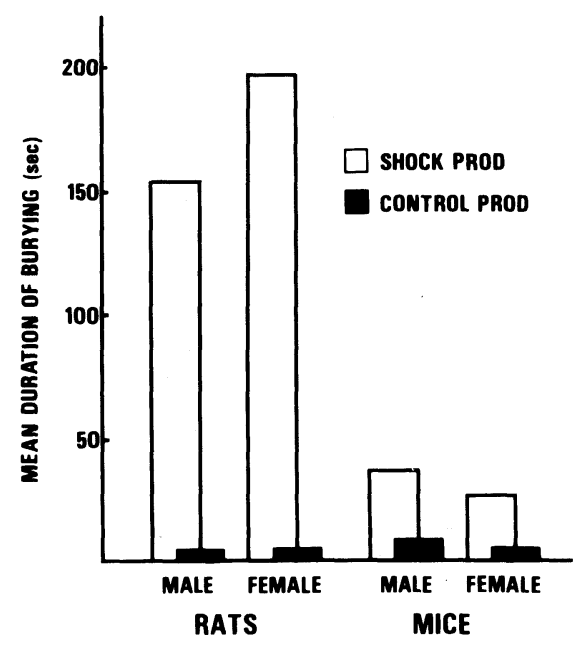

Figure 2. Mean duration of burying the shock prod and control prod by male and female Long-Evans hooded rats and CD-1 albino mice. 
$[F(3,72)=1.02, p>.30]$. Subsequent $t$ tests for dependent measures confirmed that both the male $[\mathrm{t}(9)=$ $4.42, \mathrm{p}<.002]$ and the female $[\mathrm{t}(9)=6.24, \mathrm{p}<.001]$ rats spent significantly more time burying the shock prod than they did burying the control prod, as did the male $[t(9)=3.70, p<.005]$ and female $[t(9)=4.75$, $\mathrm{p}<.001$ ] mice. Thus, the burying behavior of male and female rats and mice seemed to be controlled specifically by the association between the shock and its source (cf. Pinel, Treit, \& Wilkie, 1980).

Although rats and mice both displayed the discriminated defensive burying response, their general activity levels during the habituation and test sessions were obviously different. Both before and after the conditioning trial, the mice appeared to spend far more time running in the San-i-cel and displacing it with their hindlimbs than did any of the rats. It should be emphasized that such "random" movement of bedding did not contribute to the burying scores.

Although statistical comparisons between the rats and mice were not made, the duration of conditioned defensive burying was clearly less in the mice. At least part of this difference could be attributable to differences in the size of rats and mice relative to the test chamber. Pinel, Treit, Ladak, and MacLennan (1980) have shown that the size of the test chamber has a dramatic effect on the duration of burying. Although almost every rat in their study directed bedding at the shock prod, the duration of burying declined markedly with increases in the size of the chamber. It may be possible that the burying behavior of mice would increase significantly if they were tested in chambers smaller than those that have commonly been used to study conditioned defensive burying in rats.

\section{EXPERIMENT 3}

Under the conditions of Experiment 2, conditioned defensive burying was found to be a reliable response to localized shock in adult Long-Evans hooded rats and CD-1 mice. The purpose of Experiment 3 was to determine whether conditioned defensive burying was restricted to these particular strains or whether this form of learning is a general characteristic of these species.

\section{Method}

Twelve naive adult male subjects composed each group. They were 315- to 350 -g Long-Evans hooded rats, 326- to 375-g Wistar albino rats, $300-$ to $350-\mathrm{g}$ Fischer albino rats, 19 to $25-\mathrm{g}$ CF-1 albino mice, 30- to 35-g CD-1 albino mice, and 18- to 22-g BALB mice, purchased from Canadian Breeding Farm and Laboratories, La Prairie, Quebec. Feeding and housing conditions were comparable to those of the first two experiments, and the subjects of each strain were housed separately in groups of six.

The habituation and testing procedures were identical to those used in Experiment 2. After 4 days of habituation to the test chamber, each subject was shocked from one (black or white) of two prods mounted at opposite ends of the chamber, and the duration of burying behavior directed at the shock and control prods was recorded during the subsequent 15-min test session. As in Experiment 2, the chamber was cleaned and the bedding material was changed after each test session.

\section{Results}

As illustrated by Figure 3, all of the strains of both species of rodent displayed some burying behavior. Of the 12 subjects in each group, 11, 10, and 10 of the Wistar, Fischer, and Long-Evans rats, respectively, and 12,10 , and 6 of the CF-1, CD-1, and BALB mice, respectively, directed at least some bedding material at the shock prod.

The results of two separate analyses of variance confirmed that there was a significant effect of strain on the amount of burying directed at the shock source in both rats $[F(2,33)=4.34, p<.02]$ and mice $[F(2,33)$ $=5.86, p<.006]$. Subsequent Newman-Keuls tests $(\alpha=.05)$ of the differences between the means of the three rat strains showed that although the duration of burying behavior of Wistar rats was not significantly different from that of either Long-Evans hooded rats or Fischer rats, the Fischer rats buried significantly longer than did the Long-Evans strain. A similar analysis of the means of the three mice strains (Newman-Keuls, $\alpha=.05$ ) established that the mice of the CF-1 strain buried significantly longer than did those of either the CD-1 or the BALB strain, but no significant difference was found between the last two strains.

A series of $t$ tests for dependent measures confirmed that the burying behavior of Wistar rats $[\mathrm{t}(11)=4.55$, $\mathrm{p}<.001]$, Fischer rats $[\mathrm{t}(11)=3.63, \mathrm{p}<.002]$, LongEvans hooded rats $[\mathrm{t}(11)=2.72, \mathrm{p}<.02], \mathrm{CF}-1$ mice $[\mathrm{t}(11)=2.62, \mathrm{p}<.02]$, and $\mathrm{CD}-1$ mice $[\mathrm{t}(11)=2.17$, $\mathrm{p}<.05]$ was selective; these rodents buried the shock prod significantly more than they did the control prod. Only the BALB mice failed to display significant levels of discriminated defensive burying $[\mathrm{t}(11)=.76, \mathrm{p}>.5]$.

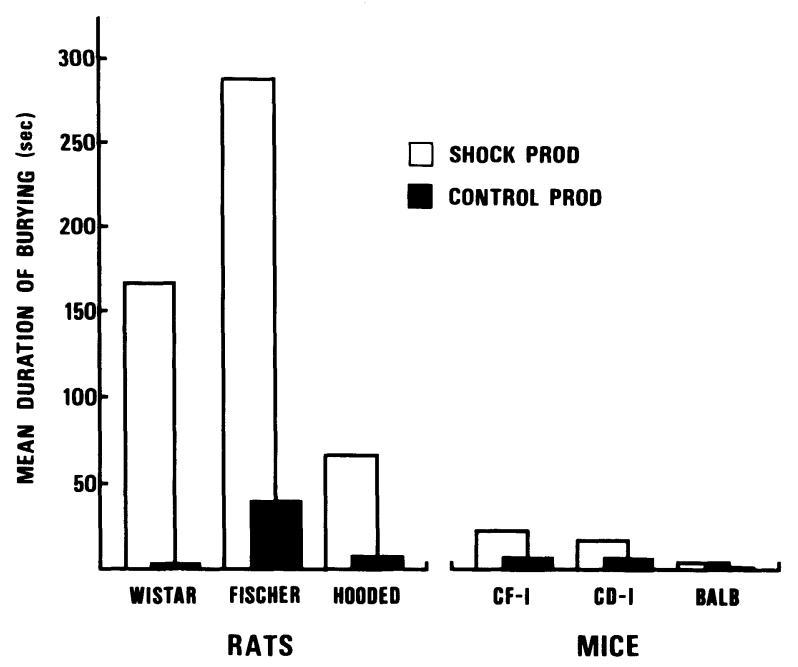

Figure 3. Mean duration of burying the shock and control prods by Wistar albino, Fischer albino, and Long-Evans hooded rats, and by CF-1, CD-1, and BALB mice. 
Thus, although conditioned defensive burying behavior was observed in all three strains of rats and in the CD-1 and CF-1 albino mice, the BALB mice did not bury the shock prod significantly more than they did the control prod. This difference offers some interesting possibilities for investigating the genetic control of defensive behavior and/or aversive conditioning in mice.

\section{GENERAL DISCUSSION}

The results of the present experiments have confirmed previous reports that conditioned defensive burying is a reliable response in adult male Long-Evans hooded rats; but, more important, they have provided evidence that the response can occur in other subjects. Significant levels of conditioned defensive burying were also observed in male and female prepubertal and postpubertal Long-Evans rats (Experiment 1), in adult male and female CD-1 albino mice and Long-Evans rats (Experiment 2), and in adult male Wistar and Fischer rats and adult male CF-1 and CD-1 albino mice (Experiment 3).

In view of the generality of conditioned defensive burying response, it is interesting that neither gerbils nor hamsters displayed even a single instance of burying and that the levels of burying in the BALB mice were negligible. However, the total absence of burying in hamsters (Whillans, 1980) and gerbils (Davis \& Rossheim, 1980) has been reported by others.

There are three possible reasons why hamsters and gerbils did not display the defensive burying response in the present context. The first possibility is that the burying response is not present in the behavioral repertoires of these animals, that is, that they do not bury under any circumstances. The second is that these animals do bury aversive stimuli but they are unable to learn the association between the prod and the shock. And the third is that they can learn the association and do bury but they did not do so under the conditions of the present experiments. Although the present experiments were not designed to differentiate among these possibilities, the major differences between rodent species in the prevalence of conditioned defensive burying may provide valuable insights into the evolution of defensive behavior and/or avoidance learning.

The finding that rats bury sources of aversive stimulation at 30 days of age, only 9 days after weaning, lends some support to the hypothesis that defensive reactions are innate (Bolles,
1970). The research of Owings and Coss (1977) on defensive behavior in ground squirrels is also consistent with this view. They found that young ground squirrels reared on a barren floor in the absence of predators sprayed sand at snakes the first time that snakes were encountered.

\section{REFERENCES}

Bolles, R. C. Species-specific defense reactions and avoidance learning. Psychological Review, 1970, 71, 32-48.

Calmoun, J. B. The ecology and sociology of the Norway rat. Bethesda, Md: U.S. Department of Health, Education, and Welfare, 1962.

Davis, S. F., \& Rosshe im, S. A. Defensive burying as a function of insulin-induced hypoglycemia and type of aversive stimulation. Bulletin of the Psychonomic Society, 1980, 16, 229-231.

Owings, D. H., \& Coss, R. G. Snake mobbing by California ground squirrels: Adaptive variation and ontogeny. Behavior, 1977, 62, 50-69.

Pinel, J. P. J., \& Treit, D. Burying as a defensive response in rats. Journal of Comparative and Physiological Psychology, 1978, 92, 708-712.

Pinel, J. P. J., \& Treit, D. Conditioned defensive burying in rats: Availability of burying materials. Animal Learning \& Behavior, 1979, 7, 392-396.

Pinel, J. P. J., Treit, D., Ladak, F., \& Maclennan, A. J. Conditioned defensive burying in rats free to escape. Animal Learning \& Behavior, 1980, 8, 447-451.

Pinel, J. P. J., Treit, D., \& Wilkie, D. M. Stimulus control of defensive burying in the rat. Learning and Motivation, 1980, 11, 150-163.

Terlecki, L. J., Pinel, J. P. J., \& Treit, D. Conditioned and unconditioned defensive burying in the rat. Learning and Motivation, 1979, 10, 337-350.

Treit, D., Pinel, J. P. J., \& Terlecki, L. J. Shock intensity and conditioned defensive burying in rats. Bulletin of the Psychonomic Society, 1980, 16, 5-7.

Wilkie, D. M., Maclennan, A. J., \& Pinel, J. P. J. Rat defensive behavior: Burying noxious food. Journal of the Experimental Analysis of Behavior, 1979, 31, 299-306.

Whillans, K. V. A comparison of conditioned defensive burying in rats and hamsters. Unpublished bachelor's thesis, University of Toronto, 1980.

(Received for publication November 13, 1980.) 